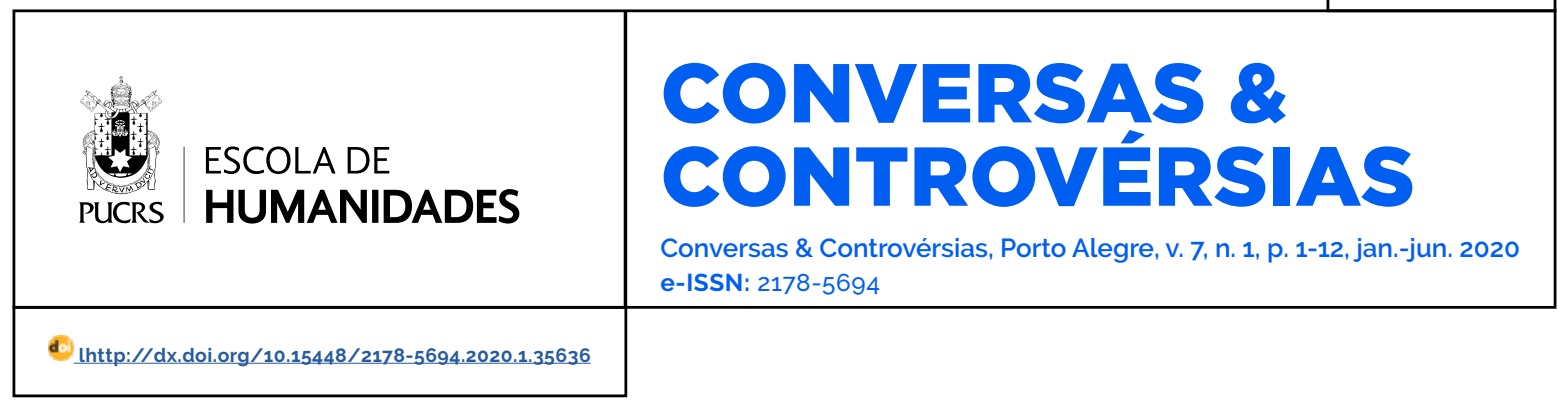

SEÇÃO: DOSSIÊ

\title{
A condição estatística da violência policial em Campinas contra jovens acusados de atos infracionais
}

\author{
The statistical condition of police violence in Campinas against \\ young people accused of infraction
}

\section{Marina de Oliveira \\ Ribeiro ${ }^{1}$ \\ orcid.org/0000-0002-4725-9138 maoliribeiro@outlook.com}

Luana Barbosa da Silva ${ }^{1}$ orcid.org/0000-0002-2338-2182 luanabarbosag8@outlook.com

Recebido em: 12 set. 2019 Aprovado em: 5 jun. 2020. Publicado em: 17 set. 2020.

\section{(c) (1)}

Artigo está licenciado sob forma de uma licença Creative Commons Atribuição 4.0 Internacional.
Resumo: O principal propósito desta pesquisa é analisar os padrões do uso da violência por agentes de segurança estatal na abordagem e na apreensão de adolescentes acusados de práticas infracionais. Para tal, realizamos uma análise quantitativa a partir de procedimentos administrativos de apuração de violência contra adolescentes por agentes de segurança pública, conduzidos e concedidos para essa pesquisa pela Promotoria de Justiça Civel de Campinas, do Ministério Público do Estado de São Paulo. A pesquisa também se direcionou qualitativamente à análise da relação entre a(as) juventude(s) e os agentes de segurança pública estatais, mais especificamente, as polícias. Para tal, utilizamos embasamentos teóricos de Jacqueline Sinhoretto, Adriana Vianna e Maria Carolina Schlittler.

Palavras-chave: Segurança pública. Juventude. Polícias. Direitos humanos. Violência.

Abstract: The main proposit of this research is to analyze the patters of violence by the agents of public security in the aprouch and arrestment of teenagers acused of infractions. For such, we realized one quantitatively analyze based on administrative procedures that investigate police brutality against teenagers made by agents of public security, those procedures where conduced by the Prosecution of Civil Justice from Campinas, of the Public Ministry of São Paulo. The research was also directed qualitatively to the analize of the relation between youth(s) and agents of public security, more specifically, the police. For such, we utilize theoretical foundations of Jacqueline Sinhoretto, Adriana Vianna and Maria Carolina Schlittler. Keywords: Public security. Youth. Police. Human rights. Violence.

\section{Introdução}

O presente artigo tem o intuito de apresentar os resultados obtidos na pesquisa "Violência policial em Campinas: processos de deslegitimação do jovem como sujeito de direitos", desenvolvida pelo grupo de pesquisa do Laboratório de Estudos sobre Política e Criminologia (PolCrim), com apoio financeiro do Conselho Nacional de Desenvolvimento Científico e Tecnológico (CNPq), na Universidade Estadual de Campinas (Unicamp). A violência policial foi analisada a partir de dados quantitativos obtidos a partir de 71 procedimentos de apuração de violência estatal concedidos pelo Ministério Público de Campinas. A hipótese de pesquisa é a de que os padrões de seletividade e de arbitrariedade no uso da violência já identificados nas práticas de agentes de segurança pública em geral se reproduzem na situação específica da cidade de Campinas, SP, Brasil. 
A importância desta discussão é evidente, quando observada a falta de dados relativos à violência estatal exercida pelos agentes de segurança pública na cidade brasileira escolhida para o estudo, Campinas, sendo que essa, atualmente, se apresenta como uma das cidades interioranas do país com mais desenvolvimento econômico, expansão territorial e altas taxas de criminalidade. ${ }^{2}$

O presente artigo, primeiramente, trata sobre os direitos da(s) juventude(s), a fim de demonstrar os referenciais teóricos relacionados à questão das juventudes e seus direitos, bem como a relação histórica dos jovens brasileiros com a polícia. Além disso, também demonstra como a polícia militar é estruturada ideologicamente e materialmente. Após o debate teórico, são expostos os dados obtidos referente aos perfis dos jovens, vítimas da violência policial, acusados de atos infracionais, como também os perfis dos agentes de segurança pública (condutores e testemunhas). Seguidamente, são apresentados mapas que apontam as localidades das ocorrências. Na conclusão, por fim, são relacionadas a hipótese da pesquisa com os resultados obtidos.

\section{Juventude(s), criminalidade e direcionamentos jurídicos}

Carmo (2017) destaca em sua pesquisa duas grandes abordagens no mundo contemporâneo acerca da juventude. A primeira a coloca como um momento problemático, demarcada pela presença da rebeldia e aos problemas comumente atrelados aos jovens, como delinquência, comportamento de risco, drogadição. Nessa concepção, todas essas características devem ser enfrentadas pelo Estado. A outra lente sobre a juventude a concebe como uma fase de transição para a vida adulta, com diversas experimentações sociais que favorecem o desenvolvimento do jovem, havendo uma transição indicada por etapas que sucederiam na personificação de papéis do mundo adulto, tais como estudante, trabalhador, chefe de familia, pai/mãe.

As duas mentalidades sobre juventude detêm grande peso no mundo juridico. No Brasil, os pri- meiros direcionamentos jurídicos sobre a juventude foram realizados no final do século XIX e início do século $X X$. Neste momento ocorriam processos históricos influentes para a política nacional, tais como a abolição da escravidão, a imigração e o processo de industrialização. Esses fenômenos sociais aumentaram a proporção de crianças e jovens pobres nas ruas das grandes metrópoles. $A$ partir de então, aumentou-se a presença do debate político formal a respeito do destino da infância e da juventude pobre e qual o protagonismo do Estado diante desse cenário (Alvarez et al. 2009).

A expansão da presença jovem nas ruas começou a ser atrelada à prática de atos ilícitos e ao aumento da criminalidade urbana (Paula 2015); deste modo, os políticos da primeira república, preocupados com a modernização da nação brasileira, interpretaram o aumento da criminalidade juvenil como uma delinquência que levaria a uma progressiva degeneração social (Alvarez et al. 2009). Essa concepção sobre a juventude e a criminalidade defendia que esses elementos deveriam ser tratados precocemente e que, para tal, o policiamento ostensivo via o controle sobre a camada social da juventude pobre deveria ser defendido e empregado em larga escala (Pimenta 2014).

Então, em 1927, foi promulgada a primeira lei de institucionalização da infância e da adolescência pelo Estado, o Código de Menores. Esse ato legislador definiu o tratamento juridico-penal especial para "certos segmentos da população considerados potencialmente perigosos, aos quais eram reservados, sobretudo, medidas disciplinadoras e moralizadoras" (Alvarez et al. 2009, XVIII).

Já em 1964, na ditadura militar, a pobreza era idealizada pelos políticos (em sua maioria militares) como uma disfunção do projeto desenvolvimentista moderno do Estado (Paula 2015). A tutela da população jovem e pobre foi amplamente defendida devido à suposta incapacidade e impotência dessas pessoas. Em vista disso, para o pleno exercício da tutela, em 1976, foi criada a Fundação do Bem-Estar do Menor em São Paulo (Febem-SP) e a internação dos jovens passou a

Marina Rossi, "Uma cidade tão rica quanto violenta", El Pais, Janeiro de 2015, https://brasil.elpais.com/brasil/2014/01/13/politica/1389645318_418014.html. 
ser efetuada em larga escala, práticas de tortura foram amplamente denunciadas nesses espaços. ${ }^{3}$

Após a ditadura, no processo de redemocratização do País, ocorreu um divisor de águas jurídicas, na qual a Constituição Federal (1988) e o Estatuto da Criança e do Adolescente (ECA) (1990) foram admitidos como uma "revolução jurídica", pois reconheceram às crianças e aos adolescentes a qualidade de sujeitos de direito (Sposato e Minahim 2011) e a tutela juridicamente foi abolida.

Com a vinda do ECA, a categoria "menor" deixou de ser utilizada na linguagem juridica oficial, sendo intimamente relacionada a práticas de tutelagem e, consequentemente, à violabilidade do direito à integridade física desses sujeitos jovens. O termo "menor", contudo, consolidou-se e manteve-se via ação policial (Vianna 1999), e outros significados relacionados ao termo, tais como "delinquentes" e "abandonados", se tornaram classificações policiais frequentemente utilizadas. Essas classificações estruturam uma distribuição simbólica de diversos "tipos" de menores a qual são sucumbidos a diferentes atuações policiais: um jovem enquadrado como um menor delinquente é mais passivel de ser violentado pela polícia, sendo que na maioria esse sujeito é interseccionado por uma classe social pobre, uma raça de cor escura e um gênero masculinizado.

A presença cotidiana da violência policial na vida da juventude negra de periferia é um dos marcadores sociais que retroalimentam desigualdades sociais. Sendo essa uma das circunstâncias pelas quais se deve admitir a diversidade da experiência de ser jovem, marcadores sociais de raça, classe, gênero e território criam diferentes narrativas, sendo impossivel constatarmos haver uma juventude, mas sim, juventudes (Carmo 2017).

Uma parte das mortes violentas, ao que tudo indica, está fortemente correlacionada à interação entre polícia e juventude. De um lado, a juventude não conta com políticas orientadas para o seu direito à vida e à segurança, especialmente a juventude negra; de outro, a juventude - especialmente a juventude negra - é o alvo privilegiado da vigilância policial, conforme indicam os dados sobre a população prisional e sobre mortes em decorrência de ação policial (Sinhoretto e Lima 2015, 124)

\section{A polícia e o tirocínio policial}

Segundo dados do Fórum Brasileiro de Segurança Pública (2017), os mortos em decorrência de ações cometidas por policiais são em geral homens, 82\% têm idade entre 12 e 29 anos e 79\% são negros. As estatisticas indicam que há um direcionamento da violência estatal para certa parcela da sociedade brasileira, sendo essa a juventude negra.

Este cenário é induzido pelo modo de definição da polícia do comportamento criminal, que fica a encargo dos policiais no trabalho cotidiano. Apesar da existência de protocolos formais padronizados, transmitidos via um saber escolarizado, para delimitar a abordagem e o uso da força para com sujeitos considerados suspeitos, o que prevalece é a prática policial do tirocinio policial (Schlittler 2016).

O saber do tirocínio policial é regido pela experiência dos policiais e fundamentado no senso comum, definida por saberes subjetivos que são apreendidos pelos policiais nas ruas e passados por eles entre gerações. Nesse saber, os sujeitos criminosos são atrelados a caracteristicas relacionadas à cultura negra, jovem, de classes pobres e periféricas (Schlitter 2016). A ação policial cotidiana acaba combinando os saberes escolarizados adquiridos pelos Procedimentos Operacionais Padrões (POP) com o saber tradicional do tirocinio. As orientações dos POP são utilizadas para a formalização das práticas e para justificá-las, mas no trabalho das ruas prevalece o tirocínio.

Ao saber do tirocinio, combina-se o protagonismo das polícias militares na gestão da segurança e da justiça, que segue a lógica do "protagonismo militarizado" (Sinhoretto e Lima 2015), esta sistematização mental da segurança pública pelos policiais mantêm uma atitude de confronto com sujeitos concebidos como bandidos, ações essas que defendem a morte destes, como inimigos.

Esse comportamento militarizado da polícia militar brasileira a dispõe como a principal protagonista

G1 SP. 2017. Justiça Condena 12 funcionários da antiga Febem por tortura, https://g1.globo.com/sao-paulo/noticia/justica-condena-12-funcionarios-da-antiga-febem-por-tortura.ghtml 
de um cenário de genocídio (Flauzina 2006) da população negra e de jovens de periferias, na qual milhares de vidas são tiradas com a justificativa de um controle da ordem e do crime (Schlitter 2016).

\section{Metodologia}

A pesquisa foi realizada com base em 75 procedimentos administrativos cedidos pela Promotoria de Justiça Cível de Campinas do Ministério Público de São Paulo. Esses procedimentos foram realizados para a apuração de supostos atos de discricionariedade administrativa relacionada à violência exercida por parte dos policiais contra adolescentes acusados de atos infracionais em Campinas.

A instauração dos procedimentos se deu após denúncias de violência policial acusadas por jovens apreendidos, perante a Promotoria de Justiça de Infância e Juventude de Campinas do Ministério Público. Dentro desses procedimentos, a pesquisa selecionou não só os boletins de ocorrência, oitivas dos jovens realizadas pela Promotoria de Infância e Juventude, como também os depoimentos dos jovens em vídeo, realizados pela Promotoria de Justiça Cível.

Os boletins de ocorrência nos possibilitaram colher informações relativas à apreensão dos jovens (localização, ato infracional, número de jovens) e à versão dos policiais sobre os fatos, logo que o histórico do ocorrido é narrado pelos policiais militares para a polícia civil que a redige nos boletins de ocorrência; já os termos de oitivas e os vídeos, nos possibilitaram acesso às denúncias de violência policial realizadas pelos jovens apreendidos, assim como suas narrativas dos acontecimentos, que nos revelaram dados como tipos de violências sofridas, instrumentos usados na violência, presença de terceiros etc.

Os procedimentos instaurados pelo Ministério Público entre 2015 e 2018 que continham todas as informações necessárias contabilizaram em 71. Para a coleta e a sistematização dos dados foi criado um formulário eletrônico na plataforma Google Forms, com perguntas relativas às condições da violência policial em Campinas; isto é, com o perfil do condutor, do jovem, do curador, da testemunha, localidades das ocorrências, atos infracionais etc.

\section{Análise dos dados}

A maior parte dos adolescentes acusados (40,57\%) tinham 17 anos no momento do registro da ocorrência. Dessa parcela, jovens de 16 anos representam 33,02\% dos 106 acusados, seguidos de jovens com 15 (16,04\%) e 14 anos (4,72\%). Adolescentes com idades inferiores a 14 e superiores a 17 anos, bem como jovens sem idade informada nos documentos analisados representam percentuais menores do total (ver Gráfico 1).

Gráfico 1 - Percentual de adolescentes acusados de ato infracional, de acordo com a idade no momento da ocorrência (Campinas, 2015-2018) ( $\mathrm{N}=106)$

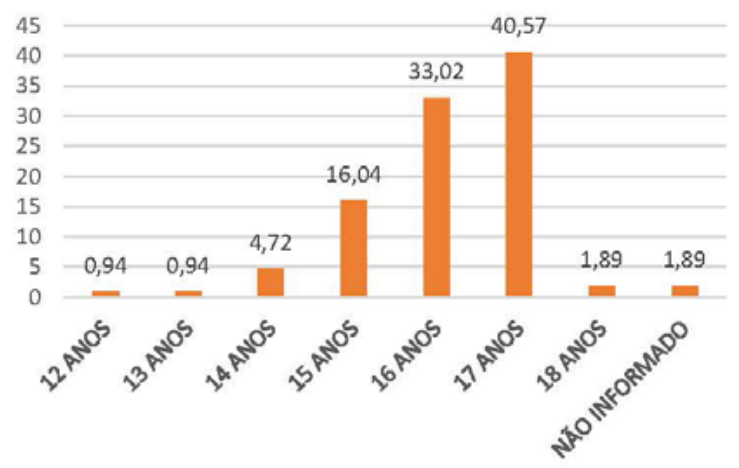

Fonte: Elaborado pelos autores com base nos dados do projeto de pesquisa "Violência policial contra adolescentes acusados de ato infracional da cidade de Campinas".

Adolescentes do sexo masculino são a ampla maioria dos acusados de atos infracionais nos procedimentos analisados: 95,28\% (ver Gráfico 2).

Gráfico 2 - Percentual de adolescentes acusados de ato infracional, de acordo com o sexo (Campinas, 2015-2018) ( $N=106)$

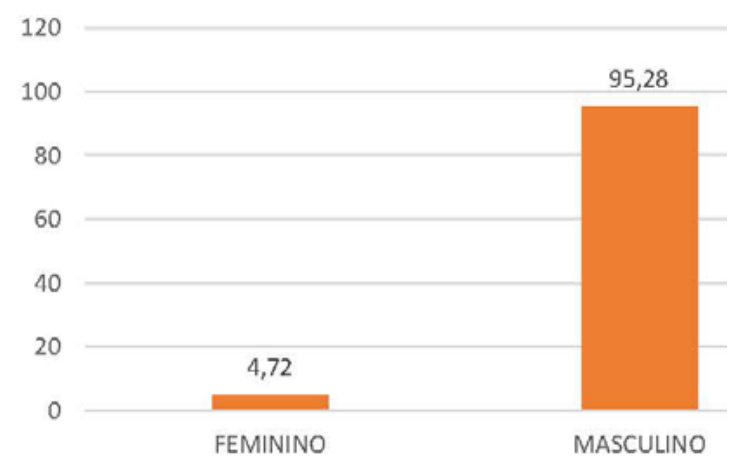

Fonte: Elaborado pelos autores com base nos dados do projeto de pesquisa "Violência policial contra adolescentes acusados de ato infracional da cidade de Campinas". 
Jovens pardos representam 48,11\% dos acusados de atos infracionais nos procedimentos analisados; 32,08\% são brancos; e 12,26\% são pretos (Gráfico 3). Não há informação de raça/cor para 5,66\% dos adolescentes identificados. Somados, pretos e pardos (negros, de acordo com as classificações oficiais) representam $60,37 \%$ dos jovens acusados.

Gráfico 3 - Percentual de adolescentes acusados de ato infracional, de acordo com a raça/cor (Campinas, 2015-2018) ( $\mathrm{N}=106)$

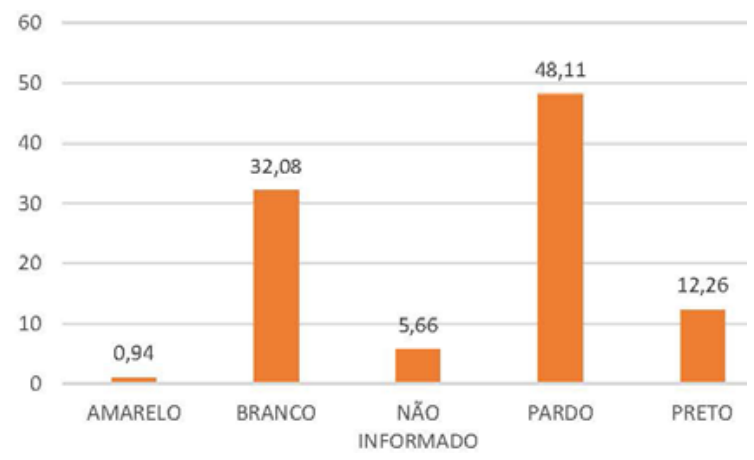

Fonte: Elaborado pelos autores com base nos dados do projeto de pesquisa "Violência policial contra adolescentes acusados de ato infracional da cidade de Campinas".

Não há informação sobre a escolaridade na identificação de $37,74 \%$ deles. Jovens com o ensino fundamental completo somam 36,79\%; com o ensino fundamental incompleto, 16,04\%. Estudantes com nivel médio incompleto representam $6,60 \%$ dos adolescentes identificados, sendo que jovens com nivel médio completo ou superior incompleto representam parcelas menores do total (ver Gráfico 4).
Gráfico 4 - Percentual de adolescentes acusados de ato infracional, de acordo com a escolaridade (Campinas, 2015-2018) ( $\mathrm{N=106)}$

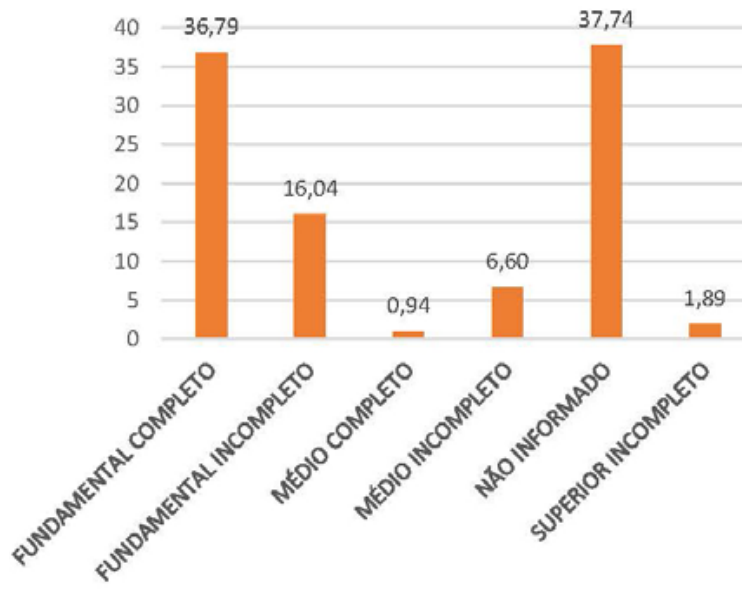

Fonte: Elaborado pelos autores com base nos dados do projeto de pesquisa "Violência policial contra adolescentes acusados de ato infracional da cidade de Campinas".

A maioria expressiva dos agentes de segurança envolvidos nos boletins de ocorrência eram policiais militares; tanto os condutores $(80,28 \%)$ quanto as testemunhas (77,46\%). Seguidos por membros da Guarda Civil Municipal, que apresenta um percentual de 9,85\% para condutores e testemunhas (Gráfico 5).

Não foram informadas as forças de segurança em 7,04\% dos casos analisados, sendo o mesmo percentual para condutores e testemunhas. Policiais civis representam 2,81\% dos casos, tanto para testemunhas quanto para condutores. Há a presença de civis (ou seja, pessoas sem vinculação às forças de segurança) apenas entre as testemunhas, e somente em 2,81\% dos casos.

Gráfico 5 - Percentual de condutores e testemunhas da apreensão, de acordo com a força de segurança na qual atuam (Campinas, 2015-2018) ( $N=71)$

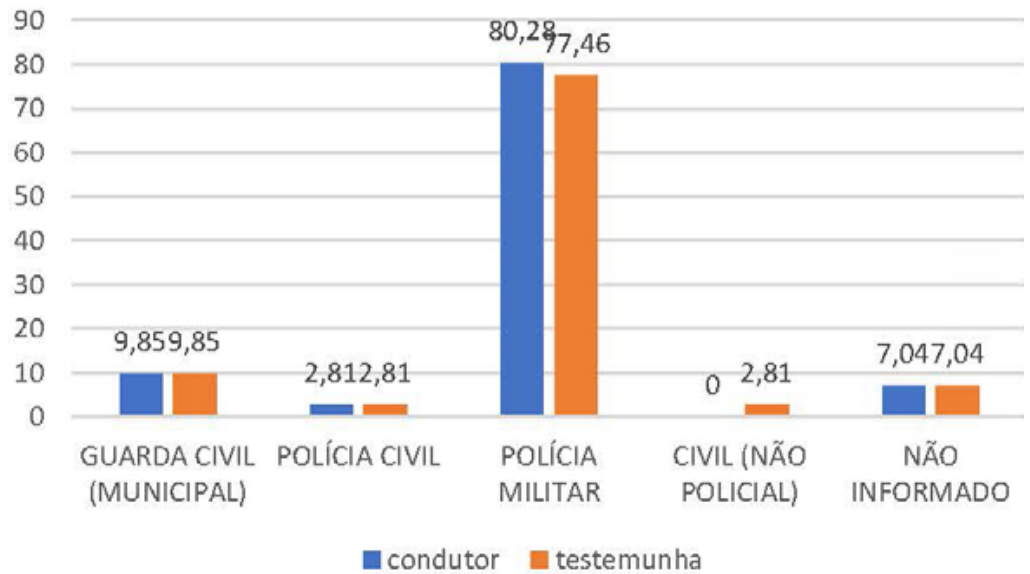

Fonte: Elaborado pelos autores com base nos dados do projeto de pesquisa "Violência policial contra adolescentes acusados de ato infracional da cidade de Campinas". 


\section{6/12 Conversas \& Controvérsias, Porto Alegre, v. 7. n. 1, p. 1-12, jan.-jun. $2020 \mid$ e-35636}

A maior parte dos atos infracionais cometidos pelos adolescentes foram classificados como roubo (28,17\%), seguidos por receptação (15,49\%), tráfico de drogas (12,68\%) e dirigir sem habilitação (11,27\%). O crime de resistência contabiliza 8,45\% dos casos, assim como posse ou porte ilegal de arma (8,45\%), seguidos por desobediência (7,04\%) - ver Gráfico 6. Os demais atos infracionais detêm porcentagens muito pequenas comparadas ao total.

Gráfico 6 - Percentual de procedimentos, de acordo com os atos infracionais registrados (Campinas, 20152018) $(N=71)$

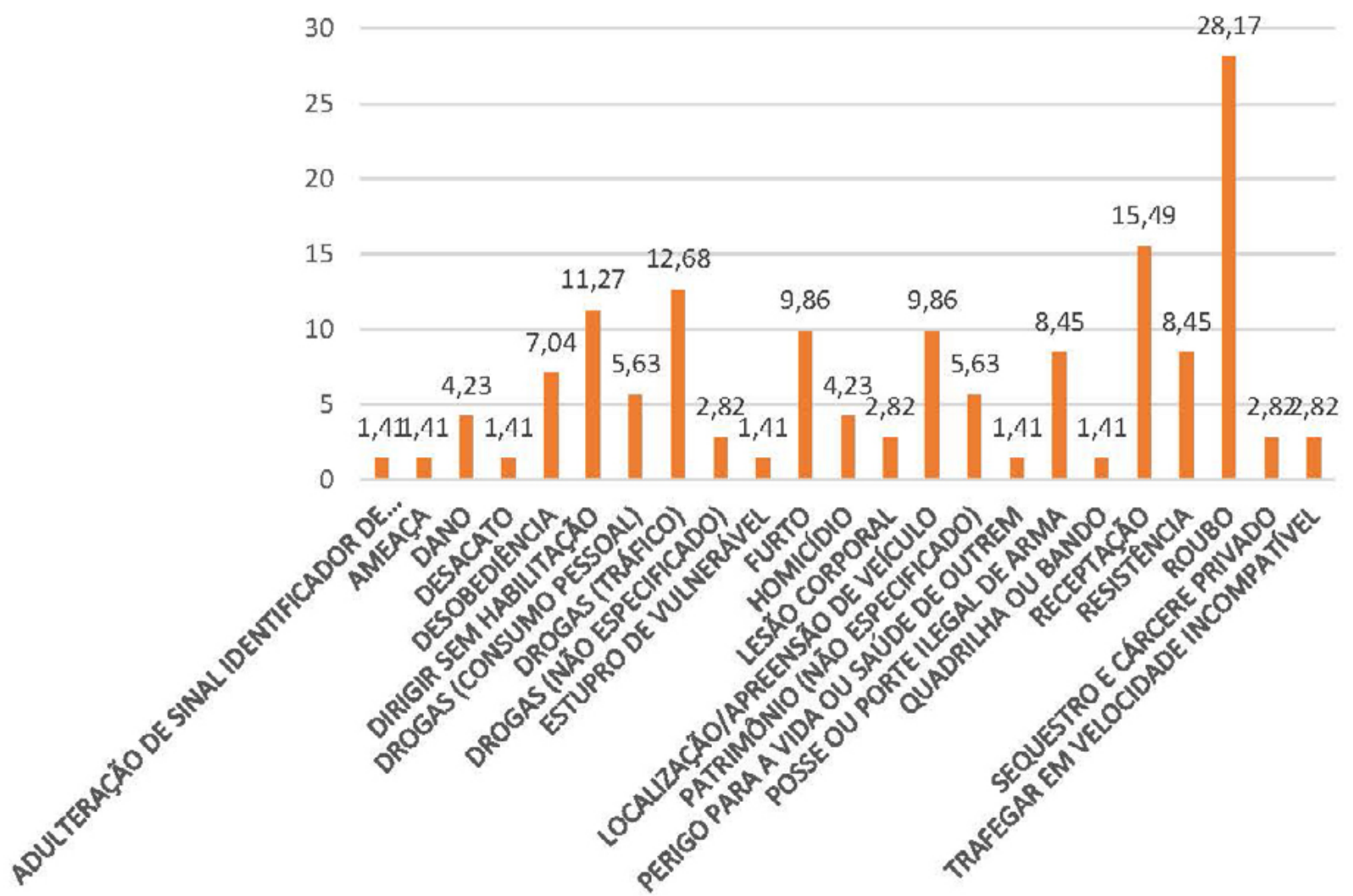

Fonte: Elaborado pelos autores com base nos dados do projeto de pesquisa "Violência policial contra adolescentes acusados de ato infracional da cidade de Campinas.

Quando agrupamos os atos infracionais em categorias (de acordo com o Código Penal e a Legislação Penal Especial) - ver Gráfico 7, os crimes contra o patrimônio representam a maioria significativa, totalizando $73,24 \%$ dos casos, seguidos por crimes de drogas (21,13\%), contra a administração pública (16,90\%), trânsito (15,49\%), contra a pessoa (14,08\%) e, em menor proporções, armas (8,45\%) e formação de quadrilha ou bando (considerado um crime contra a paz pública, mas que aqui aparece isolado e representando $1,41 \%$ dos casos). 
Gráfico 7 - Percentual de procedimentos, de acordo com os atos infracionais registrados agrupados em categorias (Campinas, 2015-2018) (N=71)

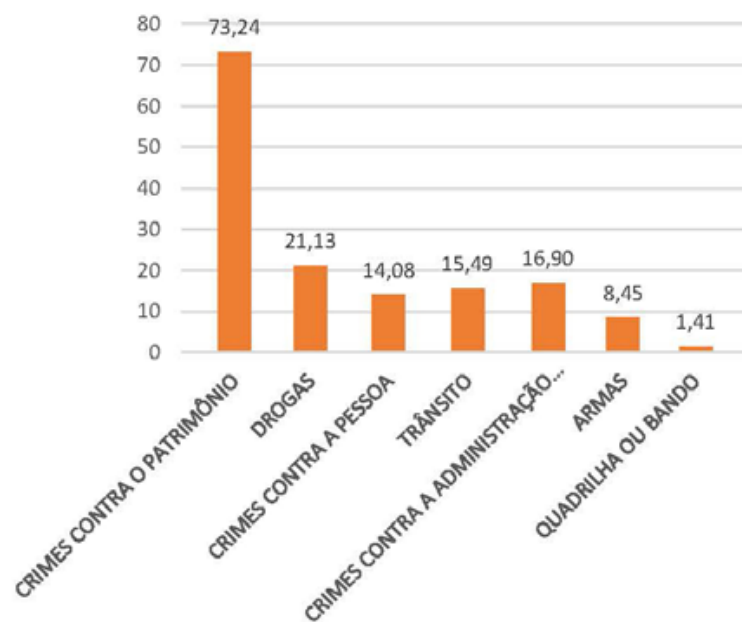

Fonte: Elaborado pelos autores com base nos dados do projeto de pesquisa "Violência policial contra adolescentes acusados de ato infracional da cidade de Campinas".

Segundo o mapa da Imagem 1, os locais de ocorrência dos atos infracionais cometidos pelos jovens estão concentrados em um raio da região do Jardim Itatinga até a região central, desse modo, prevalecem na região Sudoeste de Campinas.

Imagem 1 - Locais de ocorrência dos atos infracionais registrados (Campinas, 2015-2018) ( $\mathrm{N}=71)$

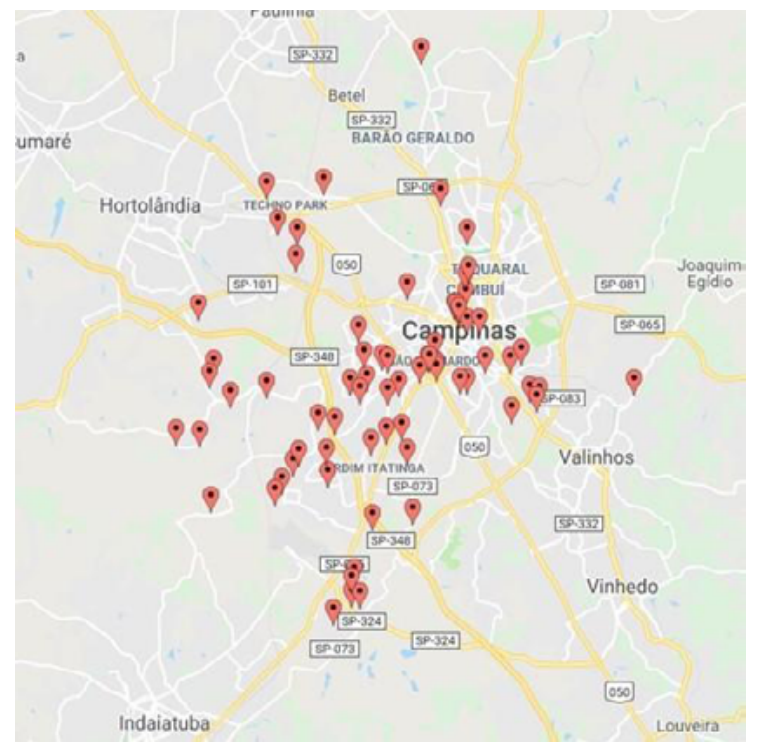

Fonte: Elaborado pelos autores com base nos dados do projeto de pesquisa "Violência policial contra adolescentes acusados de ato infracional da cidade de Campinas".
O segundo o mapa da Imagem 2, com exceção de bairros mais centrais como Cambui e Taquaral, os locais de ocorrência coincidem, em grande parte, com os locais de residência dos adolescentes apreendidos.

Imagem 2 - Locais de residência dos adolescentes (Campinas, 2015-2018) ( $\mathrm{N}=71)$

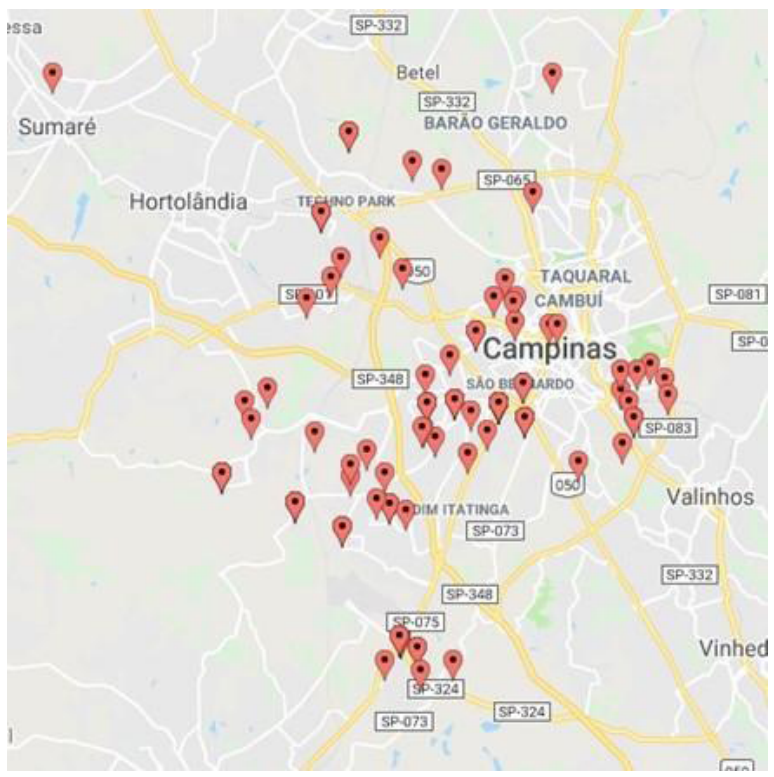

Fonte: Elaborado pelos autores com base nos dados do projeto de pesquisa "Violência policial contra adolescentes acusados de ato infracional da cidade de Campinas".

Segundo os relatos colhidos e categorizados a partir dos boletins de ocorrência, na grande maioria dos casos (77,46\%) a abordagem e apreensão dos adolescentes se deu em situação de patrulhamento de rotina (ver Gráfico 8). Em 39,44\% dos casos os policiais justificaram a abordagem pela verificação de atitude suspeita. Houve relatos de tentativa de fuga em $53.52 \%$ dos registros, sendo que em 29,58\% foi informada a perseguição de veículos. Abordagens decorrentes de ação policial no sentido de investigar ou apurar crimes anteriormente ocorridos foram informadas em 33,80\% dos procedimentos analisados, e em $18,31 \%$ os policiais estavam atendendo a chamados por rádio. Foi informada a participação de adultos nos relatos dos condutores da prisão em $9,86 \%$ dos casos, e de outros adolescentes em 1,41\% dos registros. 
Gráfico 8 - Percentual de procedimentos, de acordo com motivos e circunstâncias da abordagem, na versão dos policiais (Campinas, 2015-2018) (N=71)

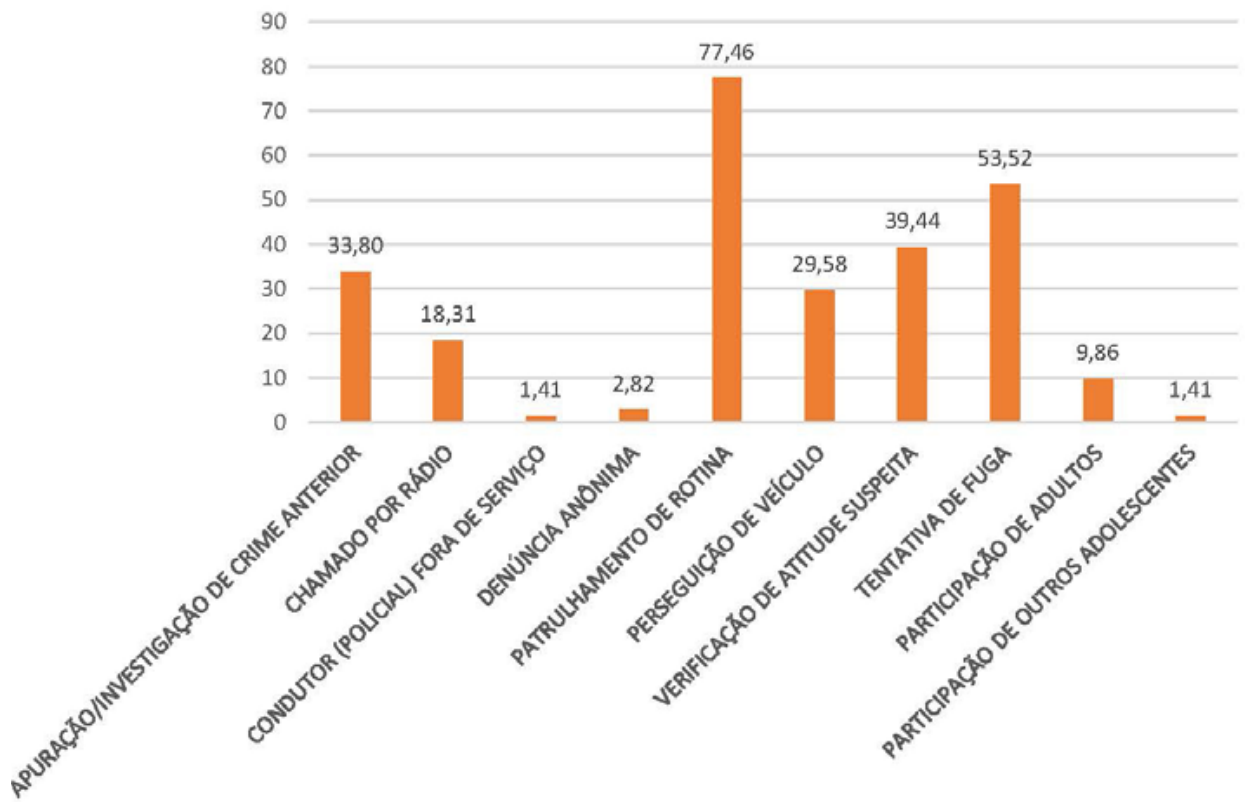

Fonte: Elaborado pelos autores com base nos dados do projeto de pesquisa "Violência policial contra adolescentes acusados de ato infracional da cidade de Campinas".

Segundo os relatos dos adolescentes apreendidos, em 71,83\% dos casos dos jovens informaram estarem na rua ou em local público e aberto no momento da abordagem; em 16,90\% dos procedimentos analisados, os jovens informaram estarem em sua residência, e em 5,63\% na residência de terceiros. Adolescentes relataram estarem indo ou voltando de atividades de lazer em 9,86\% dos casos; em 4,23\% dos procedimentos há informação de que estavam em estabelecimento comercial, e em 2,82\% de que que estavam indo ou voltando de estabelecimento comercial. A presença de adultos ou de outros adolescentes no momento da apreensão é informada em relatos presentes em $16,9 \%$ e $46,48 \%$ dos procedimentos analisados - ver Gráfico 9.

Gráfico 9 - Percentual de procedimentos, de acordo com circunstâncias da abordagem, na versão dos adolescentes (Campinas, 2015-2018) (N=71)

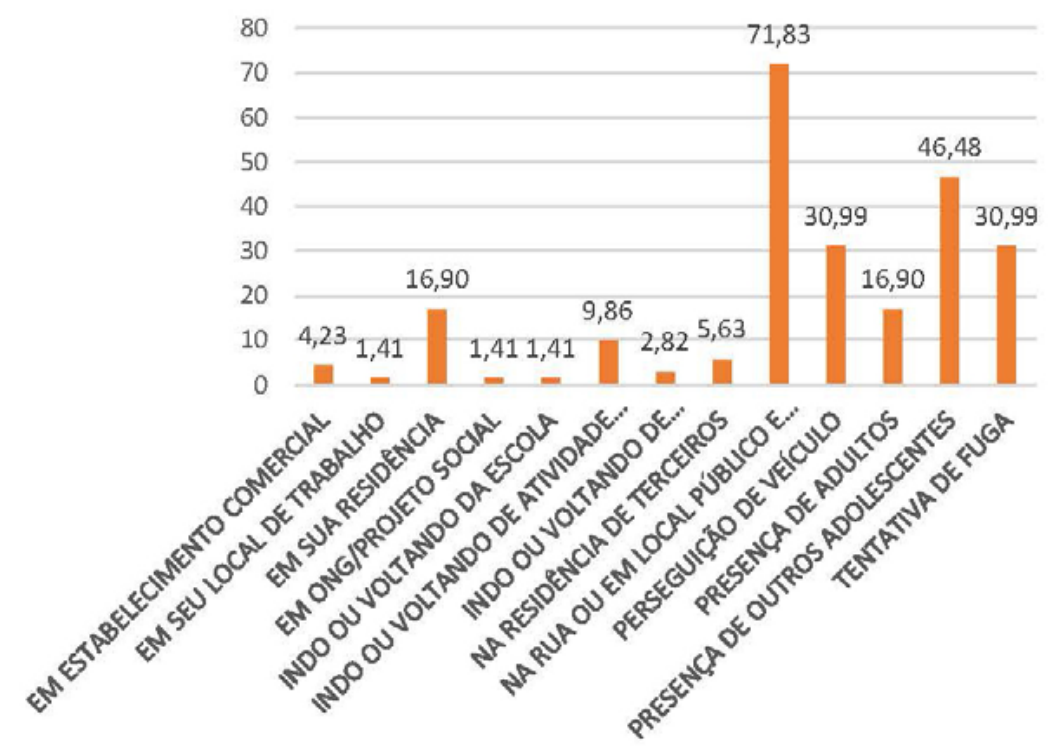

Fonte: Elaborado pelos autores com base nos dados do projeto de pesquisa "Violência policial contra adolescentes acusados de ato infracional da cidade de Campinas". 
Na coleta de dados junto aos boletins de ocorrência, foram buscadas três informações diferentes sobre a denúncia da violência policial, já no momento do registro da ocorrência e da apreensão dos adolescentes pela Polícia Civil: se há relato do adolescente sobre a violência sofrida; se houve questionamento da autoridade policial que lavrava o boletim de ocorrência sobre a prática de violência pelos autores da prisão contra o adolescente apreendido; e se houve registro formal da violência sofrida pelo adolescente no boletim de ocorrência.

Gráfico 10 - Percentual de procedimentos, de acordo com a existência de relato do adolescente, de questionamento pela autoridade policial civil e de registro no Boletim de Ocorrência da violência sofrida (Campinas, 2015-2018) ( $\mathrm{N}=71$ )

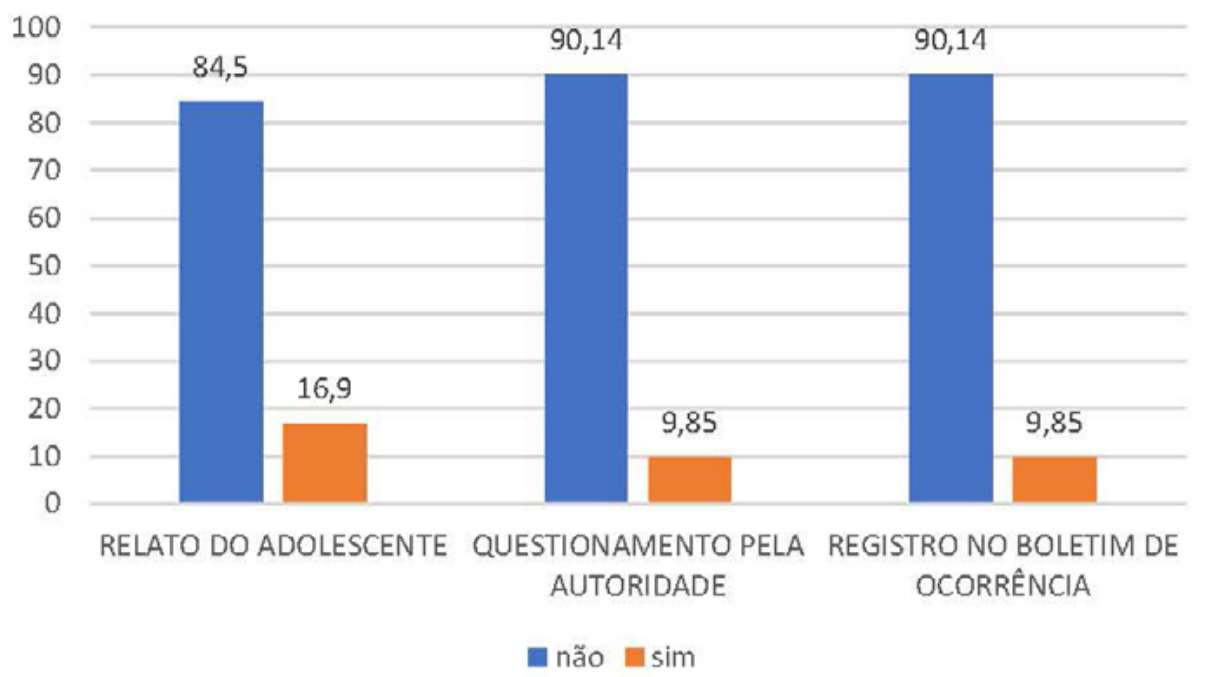

Fonte: Elaborado pelos autores com base nos dados do projeto de pesquisa "Violência policial contra adolescentes acusados de ato infracional da cidade de Campinas".

Percebe-se dos dados que, para qualquer uma das informações, o registro positivo é bastante baixo. Há relato da violência sofrida por parte do adolescente em $16,9 \%$ dos casos, mas registro dessa violência em apenas 9,85\% dos procedimentos analisados (Gráfico 10).

A violência física representa a principal forma violência utilizada pelos policiais contra os adolescentes, presente em 95,77\% dos casos analisados, seguida pela violência psicológica (35,21\%) e verbal (28,17\%) - ver Gráfico 11.
Gráfico 11 - Percentual de procedimentos, de acordo com o tipo de violência sofrida (Campinas, 20152018) $(\mathrm{N}=71)$

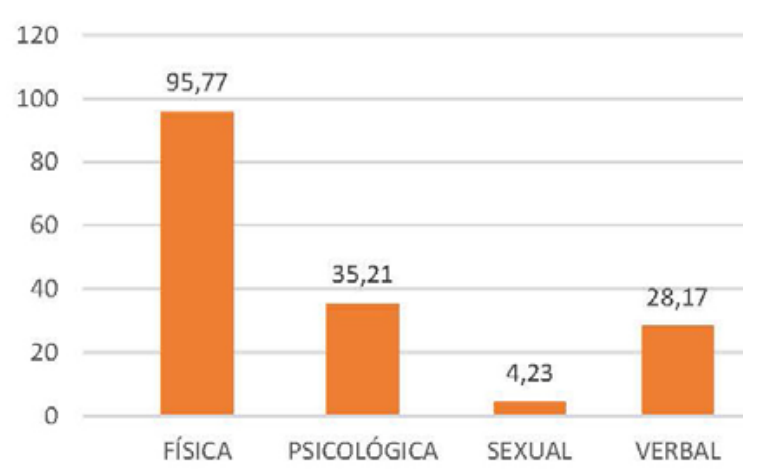

Fonte: Elaborado pelos autores com base nos dados do projeto de pesquisa "Violência policial contra adolescentes acusados de ato infracional da cidade de Campinas". 
A maioria significativa dos casos analisados envolve violência física exercida por meio de tapas, socos e chutes $(84,51 \%)$, seguidos por ofensas e gritos (33,80\%), uso de outros instrumentos (28,17\%) e ameaças de morte (23.94\%) - ver Gráfico 12.

Gráfico 12 - Percentual de procedimentos, de acordo com os meios da violência sofrida (Campinas, 20152018) $(N=71)$

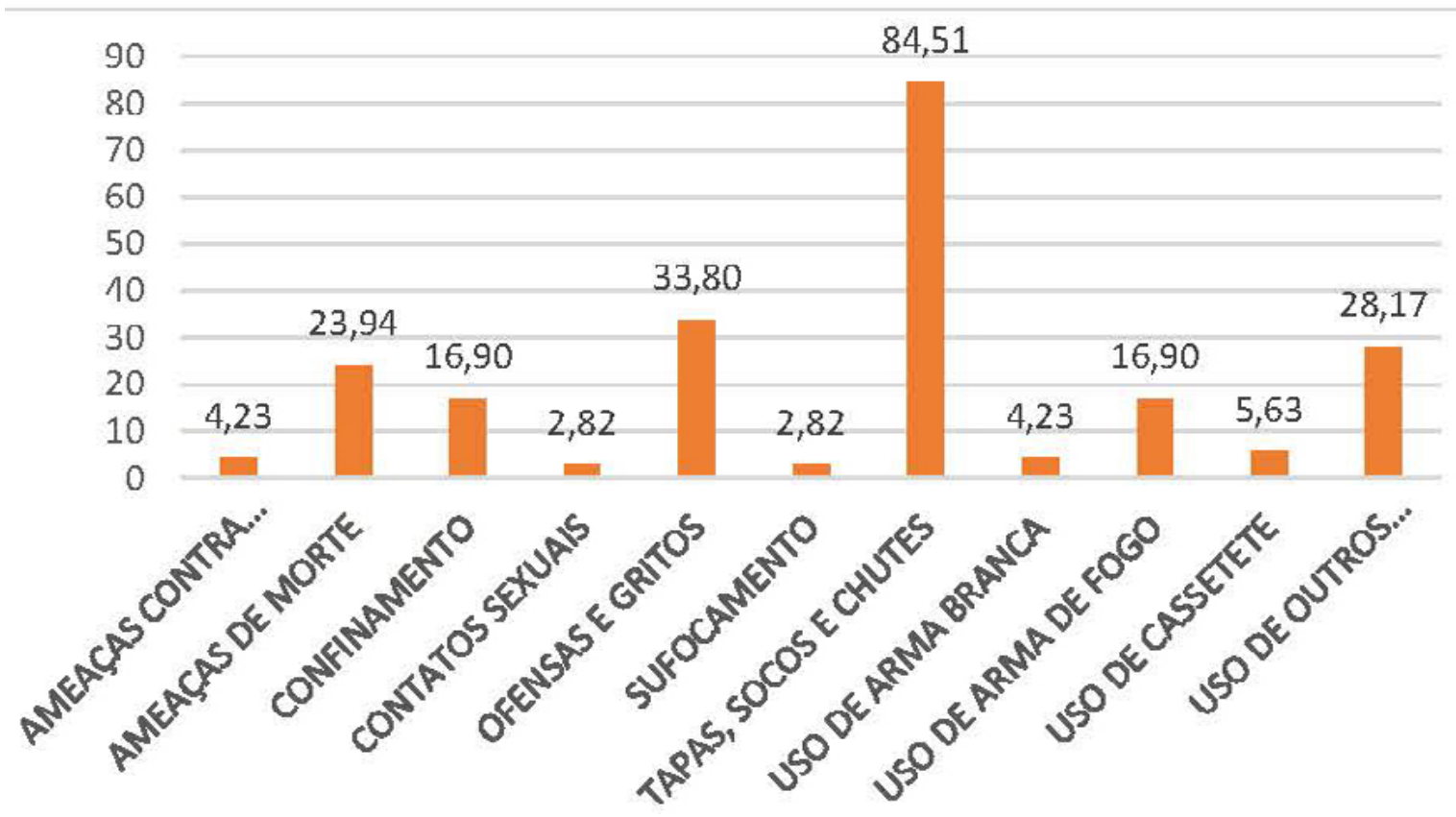

Fonte: Elaborado pelos autores com base nos dados do projeto de pesquisa "Violência policial contra adolescentes acusados de ato infracional da cidade de Campinas".

\section{Considerações finais}

Os dados adquiridos nos possibilitam afirmar que o perfil dos adolescentes vítimas de violência policial em Campinas segue o mesmo das vitimas letais de violência policial em São Paulo: jovens, negros, de baixa renda e baixa escolaridade (Sinhoretto et al. 2016). Esse mesmo perfil também é reiterado na composição do sistema carcerário brasileiro (Brasil 2014).

A ampla maioria dos jovens acusados de atos infracionais na pesquisa foram categorizados como negros (pardos e pretos), fato esse que evidencia na polícia de Campinas uma filtragem racial em sua abordagem, na qual sujeitos de pele escura são sistematicamente mais violentados pela polícia em relação aos sujeitos brancos. Esse padrão, no qual pessoas de pele escura são mais criminalizadas que as de pele clara, evidencia que o racismo é observável via a atu- ação do Estado. As lentes dos policiais (mesmo que inconsciente) associa individuos negros à criminalidade e à delinquência, utilizando a raça como categoria para diferenciar suspeitos de não suspeitos (Andrade e Andrade 2014).

Segundo dados do Censo de 2010, a região Sudoeste de Campinas é a que apresenta o pior indice de desenvolvimento humano da região municipal, com a média de 0,735 (Fundação Feac 2014). Essa localidade também é a que mais acumula registros de denúncias sobre violência policial. Em vista disso, o padrão de violência policial está vinculado aos índices socioeconômicos, localidades que concentram populações mais pobres são mais vulneráveis à ocorrência de violência estatal.

Vale ressaltar que a violência praticada contra os adolescentes é predominantemente física, mas, também é de tipo psicológica e verbal. A violência física que prevalece nos relatos foi de uso de mãos, pés e instrumentos; já a agressão 
verbal e psicológica foi via ofensas, gritos e ameaças de morte. Esse cenário expõe que a polícia se disponibiliza de um leque amplo de violências contra a juventude campineira.

Uma circunstância da criminalização da juventude campineira importante de ser ressaltado é que os tipos ilicitos dos atos infracionais supostamente cometidos pelos jovens correspondem aos crimes nos quais a maioria da população prisional brasileira é acusada, ou seja, crimes patrimoniais (principalmente roubo) e de drogas (majoritariamente tráfico) (Secretária Geral da Presidência da República 2014).

O tipo de trabalho policial também deve ser ressaltado, as suas medidas de abordagem repetem o mesmo padrão identificado em pesquisas anteriores, ressaltado como uma das características nas práticas de policiamento violento no Brasil, sendo esse o patrulhamento de rotina, via policiamento ostensivo militarizado, que por meio da "verificação de atitude suspeita" (Schlittler 2016) seleciona os grupos sociais que serão criminalizados.

O fato de que condutores e testemunhas dos casos são membros das mesmas forças policiais compromete a produção de provas e cerceia o controle da atividade de violência policial (Domenici 2019), logo que a narrativa dos policiais é a única legitimada juridicamente, pois é a presente nas documentações. Segundo os relatos dos jovens, na maioria dos casos eles estavam na rua ou em lugares públicos no momento da abordagem policial e contam que havia a presença de outros adolescentes ou adultos na apreensão, demonstrando que há a possibilidade de provas testemunhais por pessoas que não são membros de forças de segurança pública e que não estão envolvidas com a prisão.

Os registros de ocorrência realizados pela Polícia Civil não se demonstra capaz de permitir a denúncia de violências sofridas pelos adolescentes no momento de sua apreensão: mesmo quando os boletins de ocorrência incorporam relatos dos adolescentes, em poucos casos há registro formal de crime praticado pelos policiais ou mesmo questionamento expresso da autoridade policial sobre isso. Evidenciando que o registro policial apenas sustenta e formaliza as narrativas dos policiais, não apresentando avanços relativos à investigação sobre os fatos.

Os resultados da pesquisa apontam que a relação entre polícia e juventude em Campinas, no conjunto de procedimentos analisados, é baseada na seletividade social e racial praticada pela polícia, sendo, portanto, alimentada por desigualdades pré-existentes, e produzindo novas desigualdades, ao violar os direitos universalmente consagrados a todos os jovens brasileiros pela Constituição e pelo Estatuto da Criança e do Adolescente.

\section{Referências}

Andrade, Francisco, Rayane Andrade. 2014. "Raça, Crime e Justiça". Em Crime, Polícia e Justiça no Brasil, organizado por Renato Sérgio de Lima, José Luiz Ratton e Rodrigo Ghiringhelli, n. 1, 213-2019. São Paulo: Editora Contexto.

Alvarez, Marcos, Ana Lúcia Schritzmeyer, Fernando Salla, Liana de Paula, Mônica Braga. 2009. "Adolescentes em conflito com a lei: pastas e prontuários do 'Complexo do Tatuapé' (São Paulo/SP, 1990-2006)". Revista Brasileira de Adolescência e Conflitualidade 1, n. 1: xi-xxxii. https://nev.prp.usp.br/wp-content/uploads/2015/01/down232.pdf

Carmo, Milena. 2017. "Margem Adentro: políticas sociais e resistências na zona sul de São Paulo". Doutorado, Faculdade de Filosofia, Letras e Ciências Humanas, Universidade de São Paulo. https://teses.usp.br/teses/disponiveis/8/8134/tde-08022017-110349/publico/2017_MilenaMateuziCarmo_VCorr.pdf

Domenici, Thiago, luri Barcelos. 2019. "Negros são mais condenados por tráfico e com menos drogas em São Paulo". São Paulo: Pública. Acessado Agosto 05, 2019. https://apublica.org/2019/05/negros-sao-mais-condenados-por-trafico-e-com-menos-drogas-em-sao-paulo/

Fórum Brasileiro de Segurança Pública. 2017. $11^{\circ} \mathrm{Anu}$ ário Brasileiro de Segurança Pública. São Paulo: Fórum Brasileiro de Segurança Pública. https://www. forumseguranca.org.br/wp-content/uploads/2017/12/ ANUARIO_11_2017.pdf

Fundação FEAC. 2017. Diagnóstico Socioterritorial: edição 2017. Campinas, SP: Fundação FEAC. https://www.feac. org.br/wp-content/uploads/2018/07/Diagn\%C3\%B3stico-Socioterritorial-13_07_18.pdf

Flauzina, Ana Luiza. 2006. "Corpo Negro Caído No Chão: O Sistema Penal e o Projeto Genocida do Estado Brasileiro". Dissertação, Faculdade de Direito, Universidade de Brasilia. https://repositorio.unb.br/ handle/10482/5117

Paula, Liana de. 2015. "Da 'questão do menor' à garantia de direitos". Civitas 15, n. 1 (Janeiro): 27-43. https://revistaseletronicas.pucrs.br/ojs/index.php/civitas/article/download/16937/pdf_13/ https://doi. org/10.15448/1984-7289.2015.1.16937 
Pimenta, Melissa. 2014. "Juventude e Violência". In Crime, Polícia e Justiça no Brasil, organizado por Renato Sérgio de Lima, José Luiz Ratton e Rodrigo Ghiringhelli, n. 1, 220-229. São Paulo: Editora Contexto.

Schlittler, Maria Carolina. 2016. "Matar muito, prender mal': a produção da desigualdade racial como efeito do policiamento ostensivo militarizado em SP". Doutorado, Universidade Federal de São Carlos. http://bdtd.ibict.br/vufind/Record/SCAR_fa6a6ddadd5a373b24454a1087aff501

Secretária Geral da Presidência da República (Brasil). Mapa do Encarceramento: os jovens do Brasil. Brasilia: Secretária Geral da Presidência da República; PNUD.

Sinhoretto, Jacqueline, Renato Lima. 2015. "Narrativa autoritária e pressões democráticas na segurança pública e no controle do crime". Revista Contemporânea 4, n.1 (janeiro), 119-141. https://gvpesquisa.fgv.br/sites/ gvpesquisa.fgv.br/files/arquivos/sergio_lima_-_narrativa_autoritaria_-_299-696-1-sm.pdf

Sinhoretto, Jacqueline et al. 2016. "Juventude e violência policial no Município de São Paulo". Revista Brasileira Segurança Pública v.10, n.1(fev): 10-35. http:// revista.forumseguranca.org.br/index.php/rbsp/article/ download/590/226

Sposato, Karyna, Maria Auxiliadora Minahim. 2011. "A internação de adolescentes pela lente dos tribunais". Revista Direito GV 7. n. 1: 211- 298. https://Www.scielo. $\mathrm{br} /$ scielo.php?pid $=\mathrm{S} 1808=24322011000100014-\&$ scriptsci_abstract\&tlng=pt https://doi.org/10.1590/S180824322011000100014

Vianna, Adriana.1999. O mal que se adivinha: policia e menoridade no Rio de Janeiro, 1910-1920. n. 1. Rio de Janeiro: Arquivo Nacional.

\section{Marina de Oliveira Ribeiro}

Graduanda em Ciências Sociais pela Universidade Estadual de Campinas (Unicamp), em São Paulo, SP, Brasil. Bolsista (Pibic/CNPq) no projeto "Violência Policial e Juventude em Campinas: processos de deslegitimação do jovem como sujeito de direitos".

\section{Luana Barbosa da Silva}

Mestranda na Ciência Politica na Universidade de Campinas (Unicamp), em São Paulo, SP. Bolsista (Pibic/ CNPq) no projeto "Como a seletividade racial gerada pela polícia contra menores infratores gera desigualdade em suas abordagens e apreensões?". 